\title{
Evaluation of Factors Associated with Enoxaparin Therapy in South Indian Patients
}

\author{
Krishna Kumar Dhakchinamoorthi ${ }^{1}$, John Thomas Palathingal ${ }^{2}$, Muppalla Geethanjali ${ }^{3}$, Paichava Anudeep ${ }^{4}$, Kiruthiga \\ Kannan $^{4}$
}

\author{
${ }^{1}$ Professor and Head, Department of Pharmacy Practice/Pharm.D, C.L. Baid Metha College of Pharmacy, Chennai, India \\ ${ }^{2}$ Medical Science Liaison, SAM Pharmaceuticals, Nigeria \\ ${ }^{3}$ Pharma trainer, Megsan Diagnostics, Hyderabad, India \\ ${ }^{4}$ Medical Service Associate, Accenture India, Chennai, India
}

DOI: $10.36347 /$ sajp.2020.v09i10.001

| Received: 28.09.2020 | Accepted: 12.10.2020 | Published: 15.10 .2020

*Corresponding author: Dr. Krishna Kumar Dhakchinamoorthi, M. Pharm., Ph.D

\section{Abstract}

Objective: The objective of the study was to find various factors involved in enoxaparin therapy in South Indian patients. Materials \& Methods: A retrospective data analysis was carried out over six months and 203 patients received enoxaparin therapy were included for the study. All patient's data (patient demographic, past medical and medication history, and complaints on admission, laboratory parameters and medication treatment) were collected from the patient's medical records. Results: The mean age group of the study population was found to be $55.1 \pm 13.3$ $(95 \%$ CI 53.23 - 57.03) years. The mean enoxaparin dose to reach mean aPTT was found to be $2.1 \pm 1.2 \mathrm{ml}(95 \% \mathrm{CI}$ 1.89- 2.25). The mean duration of heparin therapy was 3.6 days and the time to reach aPTT was found to be 2.8 days. The average first value of aPTT was found to be $31.9 \pm 5.9(95 \% 31.11$ - 32.68) sec. The mean enoxaparin dose significantly differed between patients with different BMI groups $(\mathrm{p}<0.001)$. Stepwise univariate and multivariate linear regression analysis revealed that weight $(\mathrm{kg})$ was the major determinant $(20.6 \%)$ followed by time to reach target aPTT (12.2\%) systolic blood pressure (2.2\%), Serum creatinine (2.0\%) and Blood Urea Nitrogen (1.7\%) were the other determinants of enoxaparin dose requirements (linear regression model $\mathrm{p}<0.001)$. Conclusion: The major determinants of enoxaparin (LMWH) dose requirements were patients' body weight and time to reach the required aPTT levels, considering these factors before starting enoxaparin will improve anticoagulation outcomes in patients undergoing various surgeries.

Keywords: Enoxaparin, Low molecular weight heparin, aPTT, anticoagulation, south Indian.

Copyright (C) 2020 The Author(s): This is an open-access article distributed under the terms of the Creative Commons Attribution 4.0 International License (CC BY-NC 4.0) which permits unrestricted use, distribution, and reproduction in any medium for non-commercial use provided the original author and source are credited.

\section{INTRODUCTION}

Thromboembolism is a common lifethreatening condition among patients undergoing various surgeries (cardiovascular, neurological, total knee and hip arthroplasty and various other Surgeries) [1-3]. Anticoagulation is recommended for the prevention of thrombosis and patients at high risk [4]. The risk of venous thromboembolism is high due to increased activation of a blood coagulation system, which leads to a hyper-coagulation or risk of vascular blood clotting [5]. Anticoagulation with standard therapeutic doses significantly reduces the rate of recurrent thromboembolism and reduce morbidity [6]. Further, the risk associated with thrombosis can be reduced by the optimal use of anticoagulant as prophylactic therapy $[7,8]$.
Enoxaparin is LMWH used frequently in intensive care units [9]. LMWH or Vitamin K inhibitors were the first-line treatment for patients with pulmonary embolism [10]. LMWH preferred over other oral anticoagulants (coumarin derivatives) for preventing recurrent severe venous thromboembolism and thromboembolic events [9]. Merely, heparin is widely used as a reversible anti-coagulant in cardiovascular surgeries [11]. Further, unfractionated heparin is also used as an anti-inflammatory agent in sepsis [12] Heparin shows several advantages over LMWH such as less cost, easy to monitor, and has a simple reversal effect, however, it may cause severe bleeding than LMWH [12]. However, LMWH showed superior efficacy over unfractionated heparin for the prevention and treatment of thromboembolism [13]. 
It is very essential to monitor various anticoagulant parameters with heparin therapy, also during long-term treatment with co-administration of oral anticoagulants, other platelet inhibitors, and, antiinflammatory agents (NSAIDs) [14]. For effective anticoagulation and prevention of thromboembolism, measuring anti-Factor Xa (Anti-Xa) levels and activated partial thromboplastin time (aPTT) were recommended, however, anti-Xa leads less frequently used to monitor [15]. Achieving optimal anticoagulation with required aPTT is depending on several factors [16]. In this study, we have anticipated evaluating the association of various factors determining the aPTT values and enoxaparin dose requirement.

\section{MATERIALS AND METHODS}

The study was carried out in the department of cardiology in a tertiary care hospital located at Chennai, for six months after obtaining prior permission from the institutional committee. A retrospective data collection was carried out in 203 patients who were received enoxaparin therapy. Patient's data were collected from their case records. Patients' data were included based on the administration of enoxaparin for their clinical conditions (pre- and post-operative), aPTT value and enoxaparin dose, time to achieve the required aPTT value calculated from their baseline aPTT value. Patients' data with a history of psychiatric conditions, liver and renal complications, and the patient went for organ transplantation were excluded from the analysis. Also excluded patient data who had received any drug potentially interacting drugs with enoxaparin after the surgery.

The coagulation profile was noted and recorded for each patient from the case record. The trade names of drugs were decoded into generic names and classified based on the pharmacological class that included enoxaparin other concomitant drugs. Patients aPTT values after the surgery to maintain the enoxaparin dose was noted. Average aPTT was calculated from the three consecutive values after the surgery. Enoxaparin required dose was calculated based on their dose multiplied with total days and number of times administration for maintaining the required aPTT after the surgery.

\section{STATISTICAL ANALYSIS}

Data were analyzed using SPSS trial version 20.0 and GraphPad Instat version 3.0. All data were expressed as mean \pm S.D with a $95 \%$ confidence interval. Variations or changes in aPTT were compared between the patients' group using a student paired t-test. aPTT variability within the group before and after a set point was compared by paired t-test. The Enoxaparin mean dose was compared among the patients based on the BMI category (underweight, normal, overweight, and obese). Kruskal Wallis test was used to compare all the groups and a comparison of two groups was done by using the non-parametric Mann Whiney $U$ test.
Univariate and multivariate stepwise linear regression analysis was used to find the association of various factors with aPTT values and enoxaparin doses and other variables. For linearity, the enoxaparin dose was converted into a logarithmic dose as the dependent variable. All other parameters (age, height, weight, BMI, time to reach aPTT, other lab values) were coded as the independent variable. For all statistical analyses, p-value $<0.05$ was viewed as statistically significant.

\section{RESULTS}

The study was included 203 patients' case charts, however, 189 (87\%) patient's data included for analysis. Patients received a combination of LMWH and heparin and missing or incomplete data were excluded for analysis (13\%). The percentage of male and female ratio was found to be $61: 39$ and $42 \%$ of patients were within the age group of 50-59 years. The average age of the population was found to be $55.1 \pm 13.3$ (SD) years. The mean duration of stay of the total cohort was found to be $6.7 \pm 3.8$ days. All patients' demographic details and various laboratory investigations such as blood glucose analysis, renal parameters, hematological, and liver parameters were analyzed (Table-1). We have observed that $40 \%$ of patients were obese $(\geq 25)$ as per the Indian BMI scale. The major reason for enoxaparin anticoagulation therapy was patients with cardiovascular complications/surgery (62\%), coronary artery disease (CAD) with double vessel disease (DVD) (13.4\%), myocardial infarction (MI) (12.4\%), triple vessel disease (TVD) (12\%), acute coronary syndrome (ACS) $(10.6 \%)$ single-vessel disease (SVD) $(9.7 \%)$, and atrial fibrillation (4.2\%). Patients' blood coagulation profile was analyzed (Table.2). The mean aPTT of the total population with enoxaparin therapy was found to be $31.8 \pm 4.3 \mathrm{sec}$. The time to reach the first required aPTT was found to be $2.8 \pm 1.1$ days. Variations or changes in the aPTT was analyzed. The mean aPTT variation was found to be $0.93 \pm 1.34 \mathrm{sec}$. The difference in the aPTT variation among the various dose group $(40 \mathrm{mg}, 60 \mathrm{mg}$, $80 \mathrm{mg}$, and $120 \mathrm{mg}$ ) of enoxaparin was calculated and compared from the first value of the aPTT and after 24 hours the second value of the aPTT. There was a significant increase in aPTT (Table-3). Among the total cohort were categorized based on systolic blood pressure into prehypertensive $120-139 \mathrm{mmHg}$ (43\%), grade 1 hypertension $140-159 \mathrm{mmHg}(22 \%)$, grade 2 hypertension $\geq 160 \mathrm{mmHg}(17 \%)$, and $18 \%$ patients had normal blood pressure $(<120 \mathrm{mmHg})$. The enoxaparin dose among different groups based on BMI was compared (Figure-1). The association of various factors contributing to the enoxaparin dose requirement was analyzed by linear regression analysis (Table. 4). The significant factors $(\mathrm{p}<0.05)$ from univariate analysis were included for multivariate linear regression stepwise analysis (Table-5). The multivariate regression model revealed that weight was mostly associated with LMW enoxaparin dose $(20.6 \%)$, followed by time to reach required aPTT $(12.2 \%)$ as the second most 
predictor. Other factors $(4.7 \%)$, Systolic BP $(\mathrm{mmHg})$ $(2.2 \%)$, serum creatinine $(2.0 \%)$, Blood Urea Nitrogen $(1.7 \%)$ were contributed to a total $38.7 \%$ dose variability. In the present study, an $8 \%$ adverse drug reaction was reported (thrombocytopenia (4\%), bleeding $(3 \%)$, and bleeding with thrombocytopenia $(1 \%))$. However, there is no correlation observed with adverse drug reaction and any other factors no significant association observed with enoxaparin dose $(\mathrm{p}>0.05)$.

Table-1: Patient demographics and laboratory value details $(n=189)$

\begin{tabular}{|c|c|c|}
\hline PARAMETERS & MEAN + SD & $95 \mathrm{CI}(\%)$ \\
\hline Age (years) & $55.13 \pm 13.34$ & $53.23-57.03$ \\
\hline Gender (Male and Female) (\%) & $61 \%, 39 \%$ & $54.67-67.52,32.48-45.33$ \\
\hline Height $(\mathrm{cm})$ & $161.9 \pm 8.3$ & $160.7-163.01$ \\
\hline Weight (Kg) & $64.1 \pm 12.88$ & $62.25-65.91$ \\
\hline $\operatorname{BMI}\left(\mathrm{kg} / \mathrm{m}^{2}\right)$ & $24.3 \pm 3.93$ & $23.74-24.86$ \\
\hline Systolic BP $(\mathrm{mmHg})$ & $137.3 \pm 26.27$ & $133.56-141.45$ \\
\hline Diastolic BP (mmHg) & $80.3 \pm 13.95$ & $78.33-82.30$ \\
\hline Pulse Rate (bpm) & $86.2 \pm 18.9$ & $83.67-88.72$ \\
\hline Respiratory Rate (bpm) & $21.6 \pm 5.8$ & $20.82-22.37$ \\
\hline Temperature $\left({ }^{\circ} \mathrm{F}\right)$ & $98.8 \pm 0.7$ & $98.70-98.89$ \\
\hline Duration of Stay (days) & $6.7 \pm 3.8$ & $6.19-7.20$ \\
\hline Smoking (\%) & $22 \%$ & $12.43-26.20$ \\
\hline Alcohol (\%) & $15 \%$ & $7.72-19.60$ \\
\hline Food habit (Vegetarian and Non vegetarian) (\%) & $8 \%, 92 \%$ & $4.59-11.64,88.36-95.41$ \\
\hline \multicolumn{3}{|l|}{ Blood Glucose analysis } \\
\hline Fasting Blood Sugar (mg/dl) & $118.8 \pm 33.1$ & $114.3-123.2$ \\
\hline Post Prandial Blood Sugar $(\mathrm{mg} / \mathrm{dl})$ & $181.8 \pm 71.2$ & $180.84-182.75$ \\
\hline Random Blood Sugar (mg/dl) & $185.3 \pm 96.7$ & $172.36-198.2$ \\
\hline $\mathrm{HbA1c}(\%)$ & $8.5 \pm 2.2$ & $8.20-8.79$ \\
\hline \multicolumn{3}{|l|}{ Lipid profile analysis } \\
\hline Cholesterol (mmol/L) & $171.2 \pm 56.8$ & $163.6-178.7$ \\
\hline Triglycerides (mmol/L) & $162 \pm 68.1$ & $152.8-171.1$ \\
\hline $\mathrm{LDL}(\mathrm{mmol} / \mathrm{L})$ & $117.5 \pm 37.4$ & $112.4-122.5$ \\
\hline HDL (mmol/L) & $38.5 \pm 16.8$ & $36.25-40.74$ \\
\hline VLDL (mmol/L) & $25.7 \pm 11.9$ & $24.10-27.29$ \\
\hline \multicolumn{3}{|l|}{ Renal parameter } \\
\hline Serum Creatinine $(\mathrm{mg} / \mathrm{dL})$ & $1.2 \pm 0.953$ & $1.07-1.32$ \\
\hline Blood Urea Nitrogen (mg/dL) & $17.4 \pm 14.3$ & $15.48-19.31$ \\
\hline \multicolumn{3}{|l|}{ Liver parameter } \\
\hline AST/ SGOT (IU/L) & $28.14 \pm 54.1$ & $20.9-35.37$ \\
\hline ALT/ SGPT (U/L) & $127.3 \pm 613.3$ & $45.2-209.3$ \\
\hline ALP (IU/L) & $83.9 \pm 45.1$ & $77.86-89.93$ \\
\hline GGT (U/L) & $50.3 \pm 63.7$ & $41.77-58.82$ \\
\hline Total $(\mathrm{mg} / \mathrm{dL})$ & $1.1 \pm 1.2$ & $0.93-1.26$ \\
\hline Direct $(\mathrm{mg} / \mathrm{dL})$ & $0.4 \pm 1.4$ & $0.21-0.58$ \\
\hline Indirect $(\mathrm{mg} / \mathrm{dL})$ & $0.6 \pm 0.7$ & $0.50-0.69$ \\
\hline Total Protein $(\mathrm{g} / \mathrm{dL})$ & $7.3 \pm 1.0$ & $7.16-7.43$ \\
\hline Albumin (g/dL) & $3.4 \pm 0.7$ & $3.30-3.49$ \\
\hline Globulin $(\mathrm{g} / \mathrm{dL})$ & $3.8 \pm 1.0$ & $3.66-3.93$ \\
\hline \multicolumn{3}{|l|}{ Hematological parameters } \\
\hline RBC (cells/ $\mu \mathrm{L})$ & $4.7 \pm 2.6$ & $4.35-5.04$ \\
\hline Hemoglobin $(\mathrm{g} / \mathrm{dL})$ & $12.4 \pm 2.4$ & $12.07-12.72$ \\
\hline Total Count (mcL) & $9.9 \pm 4.1$ & $9.35-10.44$ \\
\hline Platelet $\left(10^{3} / \mathrm{ml}\right)$ & $252.8 \pm 99.5$ & $239.4-266.1$ \\
\hline MCV (f/cells) & $83.1 \pm 8.8$ & $81.92-84.27$ \\
\hline MCH (p/cells) & $28.7 \pm 6.5$ & $27.83-29.56$ \\
\hline $\mathrm{MCHC}(\mathrm{g} / \mathrm{dL})$ & $34.4 \pm 3.2$ & $33.97-34.82$ \\
\hline Hematocrit (g/dL) & $37.2 \pm 6.5$ & $36.33-38.06$ \\
\hline ESR $(\mathrm{mm} / \mathrm{hr})$ & $30.1 \pm 24.8$ & $26.78-33.41$ \\
\hline Neutrophils (cells/ $\mu \mathrm{L})$ & $68.4 \pm 13.9$ & $66.54-70.25$ \\
\hline Eosinophils (\%) & $2.6 \pm 2.0$ & $2.33-2.86$ \\
\hline Lymphocytes (\%) & $22.5 \pm 10.2$ & $21.13-23.86$ \\
\hline Monocytes $(1000 / \mu \mathrm{L})$ & $5.5 \pm 2.0$ & $5.23-5.76$ \\
\hline Polymorphs (\%) & $35.5 \pm 27.4$ & $31.83-39.16$ \\
\hline
\end{tabular}


Table-2: Coagulation Profile (n=189)

\begin{tabular}{|l|l|l|}
\hline PARAMETERS $*$ & MEAN $\mathbf{* S D}$ & 95 CI (\%) \\
\hline Bleeding time (min) & $2.0 \pm 0.1$ & $1.9-2.01$ \\
\hline Clotting time (min) & $6.6 \pm 0.5$ & $6.53-6.66$ \\
\hline Average aPTT of first value (sec) & $31.9 \pm 5.9$ & $31.11-32.68$ \\
\hline Mean aPTT of total population $(\mathrm{sec})$ & $31.8 \pm 4.3$ & $31.20-32.44$ \\
\hline Average INR & $1.1 \pm 0.3$ & $1.05-1.14$ \\
\hline Duration of therapy (days) & $3.6 \pm 1.6$ & $3.38-3.81$ \\
\hline Time to reach aPTT (days) & $2.8 \pm 1.1$ & $2.65-2.94$ \\
\hline Enoxaparin dose to reach aPTT (ml) & $2.1 \pm 1.2$ & $1.89-2.25$ \\
\hline
\end{tabular}

Table-3: Fluctuation of aPTT with enoxaparin dose $(\mathbf{n}=189)$

\begin{tabular}{|l|l|l|l|}
\hline Group based on dose $(\mathbf{m g})$ & $\mathbf{N}$ & $\mathbf{1}^{\text {st }}$ aPTT $(M e a n \pm$ SD) $(\mathbf{9 5 \%}$ CI) & $\mathbf{2}^{\text {nd }}$ aPTT $($ Mean \pm SD) $(\mathbf{9 5 \%}$ CI) \\
\hline Enoxaparin $40 \mathrm{mg}$ & 72 & $30.0 \pm 3.7(29.4-31.2)$ & $31.3 \pm 3.8(30.4-32.2)$ \\
\hline Enoxaparin $60 \mathrm{mg}$ & 33 & $32.3 \pm 5.1(30.5-34.2)$ & $33.3 \pm 5.1(31.4-35.1)$ \\
\hline Enoxaparin $80 \mathrm{mg}$ & 33 & $31.7 \pm 5.1(29.9-33.5)$ & $32.7 \pm 4.7(31.1-34.4)$ \\
\hline Enoxaparin $120 \mathrm{mg}$ & 51 & $31.8 \pm 4.2(30.6-33.1)$ & $32.6 \pm 4.2(31.4-33.8)$ \\
\hline
\end{tabular}

All enoxaparin dose groups compared after 24 hours of the first and second aPTT values, paired ' $t$ ' test was used for comparison and $\mathrm{p}<0.0001$ for all analysis.

Table-4: Univariate analysis of various parameters with required enoxaparin dose $(\mathbf{n}=189)$

\begin{tabular}{|c|l|l|l|l|l|}
\hline S.I No & Independent variable & $\mathbf{B}$ & R-value & $\mathbf{R}^{\mathbf{2}}$ value & P-value \\
\hline 1 & Height $(\mathrm{cm})$ & 1.118 & 0.235 & 0.055 & 0.001 \\
\hline 2 & Weight $(\mathrm{Kg})$ & 1.638 & 0.459 & 0.211 & $<0.0001$ \\
\hline 3 & Body Mass Index & 1.618 & 0.421 & 0.177 & $<0.0001$ \\
\hline 4 & Systolic Blood pressure $(\mathrm{mmHg})$ & 2.023 & 0.171 & 0.029 & 0.019 \\
\hline 5 & Serum Creatinine $(\mathrm{mg} / \mathrm{dL})$ & 2.318 & 0.189 & 0.036 & 0.009 \\
\hline 6 & Blood Urea Nitrogen $(\mathrm{mg} / \mathrm{dL})$ & 2.126 & 0.268 & 0.072 & $<0.001$ \\
\hline 7 & Time to reach aPTT (days) & 1.973 & 0.350 & 0.123 & $<0.0001$ \\
\hline
\end{tabular}

Table-5: Multivariate Analysis of Various Parameters with Required Enoxaparin log dose (n=189)

\begin{tabular}{|c|l|l|l|l|l|l|}
\hline S.I No & Independent variable & $\mathbf{B}$ & R-value & $\mathbf{R}^{\mathbf{2}}$ value & Adjusted R & P-value \\
\hline 1 & (Constant) & 1.277 & & & & \\
\hline 2 & Weight (kg) & 0.008 & $0.459^{\mathrm{a}}$ & 0.211 & 0.206 & $<0.0001$ \\
\hline 3 & Time to reach aPTT (days) & 0.091 & $0.579^{\mathrm{b}}$ & 0.335 & 0.328 & $<0.0001$ \\
\hline 4 & Systolic Blood Pressure (mmHg) & 0.001 & $0.600^{\mathrm{c}}$ & 0.361 & 0.350 & 0.011 \\
\hline 5 & Blood Urea Nitrogen (mg/dL) & 0.006 & $0.617^{\mathrm{d}}$ & 0.380 & 0.367 & 0.004 \\
\hline 6 & Serum Creatinine (mg/dL) & -0.068 & $0.635^{\mathrm{e}}$ & 0.403 & 0.387 & 0.009 \\
\hline
\end{tabular}

${ }^{\text {a }}$ Predictors: (Constant), Weight $(\mathrm{kg})$

b Predictors: (Constant), Weight (kg), Time to reach aPTT

${ }^{c}$ Predictors: (Constant), Weight $(\mathrm{kg})$, Time to reach aPTT, Systolic Blood Pressure (mmHg) d Predictors: (Constant), Weight $(\mathrm{kg})$, Time to reach aPTT, Systolic Blood Pressure $(\mathrm{mmHg})$, Blood Urea Nitrogen $(\mathrm{mg} / \mathrm{dL})$

e Predictors: (Constant), Weight $(\mathrm{kg})$, Time to reach aPTT, Systolic Blood Pressure $(\mathrm{mmHg})$, Blood Urea Nitrogen (mg/dL), Serum Creatinine

$$
\mathrm{n}=\mathbf{5 1}
$$

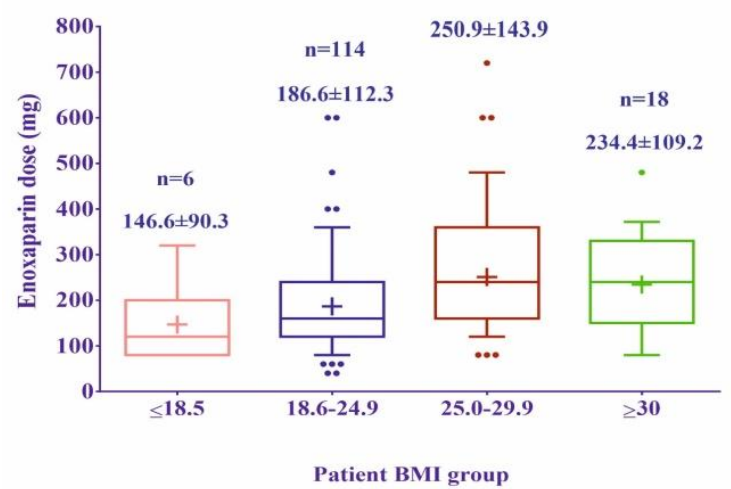

Patient BMI group

Figure-1: Comparison of required enoxaparin dose to reach aPTT based on patients BMI category $(\mathrm{n}=189)$ 
In Figure 1, box and whisker plots showing the distribution of enoxaparin dose based on BMI groups. Box and Median interquartile range (2.5-97.5 percentile), the vertical line above and below boxes minimum and maximum values, respectively, the number above the whisker mean value \pm standard deviation. The groups were compared by the nonparametric Mann Whitney U test $(\mathrm{P}<0.001)$.

\section{DISCUSSION}

The major risk factors associated with anticoagulation therapy was bleeding or thrombocytopenia or severe adverse drug event. If the optimal dose or anticoagulation isn't adequate results in failure of therapy and risk of developing thromboembolism. Parental anticoagulation therapy adequately required continuous monitoring of aPTT, anti-factor $\mathrm{Xa}$, and in the case of oral anticoagulant therapy prothrombin time (PT) and international normalized ratio (INR) were frequently monitored [16]. Different types of heparin were used as parenteral anticoagulants [17], unfractionated heparin, and low molecular weight heparin (LMWH) were most widely used. Heparin was utilized in combination with LMWH for improving aPTT levels [17]. However, LMWH has largely been used as front-line therapy instead of unfractionated heparin, due to its superior efficacy for the prevention of thrombosis [18]. In our present study, enoxaparin (LMWH) was mostly prescribed for cardiovascular surgery and other clinical condition. As age increased, elderly patients may have altered coagulation profiles [19]. The major category of patients based on age group was found to be 50-59 years old, as age increases morbidity increased, specifically in this study many patients underwent for cardiovascular surgeries. Previous studies have demonstrated that age was associated with altered heparin dosing [20]. However, in the present study, we've not found the influence of age on enoxaparin dose. Weight-based dose adjustment was recommended based on many guidelines [20,21]. However, there has been a shred of lack of evidence for the influence of the bodyweight over the enoxaparin dose. However few studies have evidenced that the body weight-based therapy significantly improves the anticoagulation therapy and dose adjustment was made considering age and BMI [20]. We've observed that BMI also a serious determinant and patients within the higher BMI (obese) required a higher dose of enoxaparin. Also, we've observed a BMI range of the total study cohort and found that $(40 \%)$ of patients were obese $(\geq 25)$.

A previous study demonstrated that including age and BMI into a weight-dependent dose predictive model, shown that heparin dosing equation had a significantly higher correlation with the predicted therapeutic dose than empiric, weight-based dosing alone. However, studies had demonstrated that weightbased dosing accounts for about $30 \%$ of dosing variability, the remaining $70 \%$ was unaccountable and cause initial dosing difficult to predict [20, 21]. Further, when patients received, unfractionated heparin reported that initiating a dose based on BMI increased the predictive value of the initial dosing [21].

In the present study, we've observed that $82 \%$ of patients were either pre or hypertensive. While analyzing the result we've found that systolic blood pressure was also a contributing factor for the enoxaparin dose requirement $(2.2 \%)$, however, we couldn't correlate the exact mechanism, the previous study demonstrated that the usage of heparin significantly reduces hypertension probably due to blood-thinning effect. Further renal parameters in our present study were observed normal, however, there's a good correlation observed with enoxaparin dose and serum creatinine $(2 \%)$. Previous studies reported that there's an indirect correlation with serum creatinine and there was a risk of increased serum creatinine during anticoagulation therapy [22, 23]. Our study was in agreement with the previous study; serum creatinine inversely correlated and reduces the enoxaparin dose requirement. Further, the protein level albumin, globulin, and total protein weren't significantly related to the enoxaparin dose. The bleeding time was very low than the normal range and clotting time indicates a slightly high level than the normal range.

The major factor determining the dose of enoxaparin was time to reach in required aPTT. In the present study, the time to reach in aPTT above the normal was noted as the first aPTT above normal. However, the patient required enoxaparin dose was two days (48 hours). Further, we've observed that there's a significant increase in aPTT level when continuing the dose and frequency of administration. This results in coagulation therapy with significant adverse enoxaparin effect (bleeding, thrombocytopenia, etc.,), hence the dose or frequency was reduced [24]. There was no association with any factors and enoxaparin dose, to manage adverse drug reaction the dose was reduced and adjusted and platelet count was monitored. However, several factors weren't related to the enoxaparin dose. Patients with chronic renal failure may require monitoring anti-factor $\mathrm{Xa}$ because renal dysfunction may prolong the half-life of low-molecular-weight heparin due to elimination dysfunction. Studies were reported that anti-factor $\mathrm{Xa}$ is more accurate but not stable, also the value of testing is going to be more costly, and frequent monitoring increases the burden to patients $[15,25]$. Patients with concomitant medication after the surgery with enoxaparin were at higher risk of developing adverse drug reactions due to higher interacting property of enoxaparin. Various drugs with enoxaparin can cause bleeding [26, 27].

The limitation of the present study we have conducted in a retrospective data analysis to observe the effect of various factors. However, a comparison of the coagulation factors at each time point and correlation of 
incremental dose and aPTT change was not established. In the present regression model, only $38 \%$ of correlation was observed, the remaining $62 \%$ of the variation was unaccounted. Further prospective studies and randomized controlled studies provide a more accurate correlation of various factors.

Patients receiving enoxaparin therapy require continuous monitoring and the dose will be adjusted considering patients' body weight, time to reach the normal aPTT levels, patients' serum creatinine level, and blood urea nitrogen may be monitored to improve the prediction of enoxaparin dose in south Indian patients and prevent anticoagulant associated complications.

\section{ACKNOWLEDGEMENT}

Clinical Pharmacologist, Nursing staffs, and Junior doctors are gratefully acknowledged.

Conflicts of Interest: There are no conflicts of interest.

\section{REFERENCES}

1. Kingue S, Bakilo L, Mvuala R, Minkande JZ, Fifen I, Gureja YP, Razafimahandry HJ, Okubadejo N, Oke DA, Manga A, Rajaonera T. Epidemiological African day for evaluation of patients at risk of venous thrombosis in acute hospital care settings. Cardiovascular journal of Africa. 2014 Jul;25(4):159-64.

2. Moayer A, Mohebali N, Razmkon A. Incidence of Deep Vein Thrombosis in Patients Undergoing Degenerative Spine Surgery onProphylactic Dalteparin; A Single Center Report. Bull Emerg Trauma. 2016; 4:38-42.

3. Kawai Y, Fuji T, Fujita S, Kimura T, Ibusuki K, Abe K, Tachibana S. Edoxaban versus enoxaparin for the prevention of venous thromboembolism after total knee or hip arthroplasty: pooled analysis of coagulation biomarkers and primary efficacy and safety endpoints from two phase 3 trials. Thrombosis Journal. 2016 Dec 1;14(1):48.

4. Costantini TW, Min E, Box K, Tran V, Winfield RD, Fortlage D, Doucet J, Bansal V, Coimbra R. Dose adjusting enoxaparin is necessary to achieve adequate venous thromboembolism prophylaxis in trauma patients. The journal of trauma and acute care surgery. 2013 Jan;74(1):128-133.

5. Christensen TD, Vad H, Pedersen S, Hornbech K, Zois NE, Licht PB, Nybo M, Hvas AM. Coagulation profile in patients undergoing videoassisted thoracoscopic lobectomy: A randomized, controlled trial. PLoS One. 2017 Feb 15;12(2):e0171809.

6. Huang W, Anderson FA, Rushton-Smith SK, Cohen AT. Impact of thromboprophylaxis across the US acute care setting. PloS One. 2015; 10:e0121429.

7. Beall J, Woodruff A, Hempel C, Wovkulich M, Zammit K. Efficacy and Safety of High-Dose
Subcutaneous Unfractionated Heparin Prophylaxis for the Prevention of Venous Thromboembolism in Obese Hospitalized Patients. Hosp Pharm. 2016; 51:376-81.

8. Robinson S, Zincuk A, Larsen UL, Ekstrøm C, Nybo M, Rasmussen B, Toft P. A comparative study of varying doses of enoxaparin for thromboprophylaxis in critically ill patients: a double-blinded, randomised controlled trial. Critical Care. 2013 Apr 1;17(2):R75.

9. Lee AY, Bauersachs R, Janas MS, Jarner MF, Kamphuisen PW, Meyer G, Khorana AA. CATCH: a randomised clinical trial comparing long-term tinzaparin versus warfarin for treatment of acute venous thromboembolism in cancer patients. BMC cancer. 2013 Dec 1;13(1):284.

10. Lee AY, Levine MN, Baker RI, Bowden C, Kakkar AK, Prins M, Rickles FR, Julian JA, Haley S, Kovacs MJ, Gent M. Low-molecular-weight heparin versus a coumarin for the prevention of recurrent venous thromboembolism in patients with cancer. New England journal of medicine. 2003 Jul 10;349(2):146-53.

11. Jia Z, Tian G, Ren Y, Sun Z, Lu W, Hou X. Pharmacokinetic model of unfractionated heparin during and after cardiopulmonary bypass in cardiac surgery. J Transl Med. 2015; 13:45.

12. Nouri M, Ahmadi A, Etezadi F, Barzegar E, Mojtahedzadeh M. Comparison of the Effects of Subcutaneous Versus Continuous Infusion of Heparin on Key Inflammatory Parameters Following Sepsis. Anesthesiol Pain Med. 2016; 6:e33780.

13. Mahan CE, Pini M, Spyropoulos AC. Venous thromboembolism prophylaxis with unfractionated heparin in the hospitalized medical patient: the case for thrice daily over twice daily dosing. Intern Emerg Med. 2010; 5:299-306.

14. Pranckeviciene G, Kadusevicius E, Putniene A. Influence of coadministration of antithrombotic medicines, warfarin, and NSAIDs on heparin safety: data from a prospective observational study. J Manag Care Pharm JMCP. 2013; 19:47886.

15. Thomas O, Lybeck E, Strandberg K, Tynngård N, Schött U. Monitoring low molecular weight heparins at therapeutic levels: dose-responses of, and correlations and differences between aPTT, anti-factor $\mathrm{Xa}$ and thrombin generation assays. PloS One. 2015; 10:e0116835.

16. Chlebowski MM, Baltagi S, Carlson M, Levy JH, Spinella PC. Clinical controversies in anticoagulation monitoring and antithrombin supplementation for ECMO. Crit Care [Internet]. BioMed Central; 2020 [cited 2020 Mar 21];24. Available from: https://www.ncbi.nlm.nih.gov/pmc/articles/PMC6 971875/

17. Jacobs BN, Cain-Nielsen AH, Jakubus JL, Mikhail JN, Fath JJ, Regenbogen SE, Hemmila MR. 
Unfractionated heparin versus low-molecularweight heparin for venous thromboembolism prophylaxis in trauma. The journal of trauma and acute care surgery. $2017 \mathrm{Jul} ; 83(1): 151-158$.

18. Junqueira DR, Zorzela LM, Perini E. Unfractionated heparin versus low molecular weight heparins for avoiding heparin-induced thrombocytopenia in postoperative patients. Cochrane Database Syst Rev. 2017; 4:CD007557.

19. Shishina RN, Pchelintseva TA. Age-related clinical and laboratory features of patients with occluded main arteries of lower extremities. Klin Med (Mosk). 2013; 91:45-9.

20. Schurr JW, Muske A-M, Stevens CA, Culbreth SE, Sylvester KW, Connors JM. Derivation and Validation of Age- and Body Mass IndexAdjusted Weight-Based Unfractionated Heparin Dosing. Clin Appl Thromb Off J Int Acad Clin Appl Thromb. 2019; 25:1076029619833480.

21. Schurr JW, Stevens CA, Bane A, Luppi C, Culbreth SE, Miller AL, Connors JM, Sylvester KW. Description and evaluation of the implementation of a weight-based, nurse-driven heparin nomogram in a tertiary academic medical center. Clinical and Applied Thrombosis/Hemostasis. 2018 Mar;24(2):248-53.

22. Fox KA, Antman EM, Montalescot G, Agewall S, SomaRaju B, Verheugt FW, Lopez-Sendon J, Hod $\mathrm{H}$, Murphy SA, Braunwald E. The impact of renal dysfunction on outcomes in the ExTRACT-TIMI
25 trial. Journal of the American College of Cardiology. 2007 Jun 12;49(23):2249-55.

23. Nagge J, Crowther M, Hirsh J. Is impaired renal function a contraindication to the use of lowmolecular-weight heparin? Arch Intern Med. 2002; 162:2605-9.

24. Kalpatthi R, Kiss JE. Thrombotic Thrombocytopenic Purpura, Heparin-Induced Thrombocytopenia, and Disseminated Intravascular Coagulation. Crit Care Clin. 2020; 36:357-77.

25. Byun JH, Jang I-S, Kim JW, Koh EH. Establishing the heparin therapeutic range using aPTT and antiXa measurements for monitoring unfractionated heparin therapy. Blood Res. 2016; 51:171-4.

26. Juárez Cedillo $\mathrm{T}$, Martinez Hernández $\mathrm{C}$, Hernández Constantino A, Garcia Cruz JC, Avalos Mejia AM, Sánchez Hurtado LA, Islas Perez V, Hansten PD. Clinical weighting of drug-drug interactions in hospitalized elderly. Basic \& Clinical Pharmacology \& Toxicology. 2016 Apr;118(4):298-305.

27. Fettah H, Moutaouakkil Y, Sefrioui MR, Moukafih B, Bousliman Y, Bennana A, Lamsaouri J, Makram S, Cherrah Y. Detection and analysis of drug-drug interactions among hospitalized cardiac patients in the Mohammed V Military Teaching Hospital in Morocco. Pan African Medical Journal. 2018;29(1):1-6. 